УДК 621.771 .2

Медведев В. С. Базарова Е. B.

\title{
МАТЕМАТИЧЕСКАЯ МОДЕЛЬ ФОРМОИЗМЕНЕНИЯ МЕТАЛЛА В ЧЕРНОВЫХ ЗАКРЫТЫХ БАЛОЧНЫХ КАЛИБРАХ
}

Закрытые балочные калибры (рис. 1) применяются на сортовых станах при производстве двутавровых профилей широкого сортамента. Данные калибры располагаются в черновых клетях станов, где из прямоугольной заготовки за несколько проходов формируют подкаты двутавровой формы со стенкой и достаточно высокими фланцами. Основным недостатком этих калибров является трудность получения одинаковой высоты фланцев вследствие разного характера деформации металла в открытых и закрытых элементах калибров. Исправить асимметрию чернового двутаврового подката на последующих этапах технологического процесса в чистовых калибрах весьма затруднительно. Поэтому, для повышения точности готовых двутавровых профилей, в первую очередь необходимо обеспечить высокую точность фасонных подкатов в черновых калибрах. Для решения этой задачи разработчик технологии должен располагать надежными методами расчета формоизменения металла в калибрах.

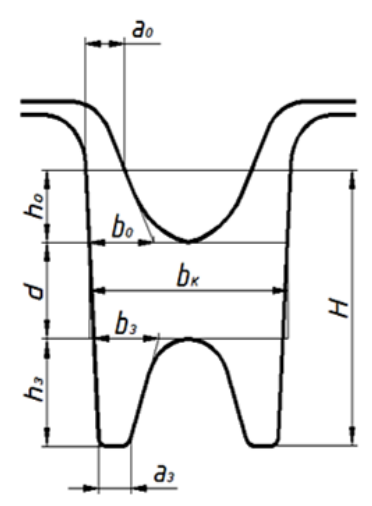

Рис. 1. Черновой закрытый балочный калибр

Однако процесс прокатки в черновых закрытых балочных калибрах изучен недостаточно полно. Исследования разрознены и носят частный характер, не установлено влияние различных технологических факторов прокатки на формоизменение металла, особенно в калибрах с отношением толщины стенки $d$ к высоте профиля $H$ в пределах от 0,2 до 0,4 (область не исследованных калибров). Проблема повышения точности прокатки двутавровых профилей может быть решена при условии установления физических закономерностей формоизменения металла в балочных калибрах и разработки научно-обоснованных методов проектирования калибровок валков.

В работах В. С. Медведева, В. А. Шпакова и Е. В. Базаровой [1-4] приведены результаты комплексных теоретических и экспериментальных исследований процесса прокатки в черновых закрытых балочных калибрах. С использованием метода конечных элементов и программного комплекса SIMULIA/ABAQUS выполнен анализ напряженно-деформированного состояния металла в калибрах, установлены общие закономерности пластического течения металла, определено влияние основных технологических факторов процесса прокатки (распределения обжатий по элементам профиля и геометрических параметров очага деформации) на высотную деформацию фланцев. Авторами получены количественные оценки оптимальных граничных параметров прокатки профилей и калибровок валков на начальной стадии технологического процесса. Прокатка профилей с оптимальными граничными параметрами 
позволяет сформировать в черновых калибрах двутавровый раскат с максимально возможной высотой открытых и закрытых фланцев, а на последующих заключительных стадиях технологического процесса в предчистовых контрольных калибрах обеспечить надежное высотное обжатие фланцев и далее в чистовом универсальном калибре получить готовые двутавровые профили с точными размерами по ширине полок. Изменяя параметры прокатки в черновых калибрах, можно управлять высотной деформацией фланцев и регулировать ширину полок на готовом профиле, т. е. фактически прогнозировать и управлять конечным формоизменением металла для повышения точности прокатки двутавровых профилей. Результаты теоретических исследований подтверждены экспериментально путем физического моделирования процесса прокатки на составных свинцовых образцах с координатными сетками [5].

В настоящей статье изложены результаты заключительного этапа теоретических исследований авторов.

Целью данной работы является разработка математической модели формоизменения металла в закрытых балочных калибрах с отношением толщины стенки $d$ к высоте профиля $H$, равным $0,2-0,4$.

Анализ действующих калибровок валков для производства двутавровых профилей показывает, что в черновых закрытых балочных калибрах происходит интенсивное увеличение высоты открытых и закрытых фланцев при уменьшении высоты полок (общей высоты профиля). Для получения двутаврового раската с максимально высокими фланцами течение металла в направлении высоты открытых и закрытых фланцев стенками калибров не ограничивают, уширение металла здесь является свободным. Точный прогноз положения свободных поверхностей металла в открытых и закрытых фланцах является основной задачей калибровщика.

Интегральными количественными характеристиками, с помощью которых можно однозначно определить положение свободных поверхностей, являются безразмерные параметры: коэффициенты высотной деформации полки $\eta_{H}=H / H^{\prime}$, открытого фланца $\eta_{h o}=h_{o} / h_{o}^{\prime}$ и закрытого $\eta_{h s}=h_{3} / h_{3}^{\prime}$, а также абсолютное значение деформации высоты полок $\Delta H=H-H^{\prime}$ (утяжка полок) и абсолютное приращение высоты открытых фланцев $\Delta h=h_{o}^{\prime}-h_{o}$ и закрытых $\Delta h=h_{3}^{\prime}-h_{3}$. Здесь $H_{\text {и }} H^{\prime}$ - высота полки, $h_{o}$ и $h_{o}^{\prime}$ - высота открытого фланца, $h_{3}$ и $h_{3}^{\prime}$ - высота закрытого фланца (здесь и далее по тексту: размеры без штриха до прокатки, со штрихом - после прокатки).

Деформация металла в направлениях, где нет ограничения стенками калибров, зависит от формы и размеров профиля (геометрических параметров очага деформации) и распределения обжатий по его элементам (прямого обжатия стенки и бокового обжатия фланцев). Это основные технологические факторы процесса прокатки, влияющие на высотную деформацию фланцев.

Деформация по толщине элементов профиля характеризуется следующими безразмерными параметрами: коэффициент обжатия стенки по толщине $\eta_{d}=d / d$, коэффициенты бокового обжатия открытого фланца $\eta_{t o}=t_{o} / t_{o}^{\prime}$ и закрытого $\eta_{t 3}=t_{3} / t_{3}^{\prime}$, а также средний по всему калибру коэффициент бокового обжатия открытых и закрытых фланцев $\eta_{t}=0,5\left(\eta_{t o}+\eta_{t 3}\right)$. Здесь $d$ и $d^{\prime}$ - толщина стенки, $t_{o}$ и $t_{o}^{\prime}-$ средняя толщина открытого фланца, $t_{3}$ и $t_{3}^{\prime}$ - средняя толщина закрытого фланца.

Форма двутавра характеризуется безразмерными параметрами: $B / d$ - отношение ширины профиля $B$ к толщине стенки $d ; B / H$ - отношение ширины профиля $B$ к высоте полок $H$.

Теоретическое исследование деформированного состояния металла проводили на модели чернового закрытого калибра для двутавра № 16, прокатываемого на крупносортном стане 650 Мариупольского металлургического комбината ЧАО «МК «Азовсталь». Модель калибра и соответствующей исходной фасонной заготовки, выполненные в масштабе 1:2, 
показаны на рис. 2. Данный калибр выбран в качестве базового. Расчеты произведены для стали СтЗсп при температуре $1100{ }^{\circ} \mathrm{C}$ и скорости прокатки 1,0 м/с. Результаты теоретических расчетов высотной деформации полок $\eta_{H}$ и фланцев $\eta_{h o}, \eta_{h з}$ при изменении технологических факторов прокатки $\eta_{d}, \eta_{t}, B / d$ и $B / H$ представлены массивом первичных данных в табл. 1 .



a

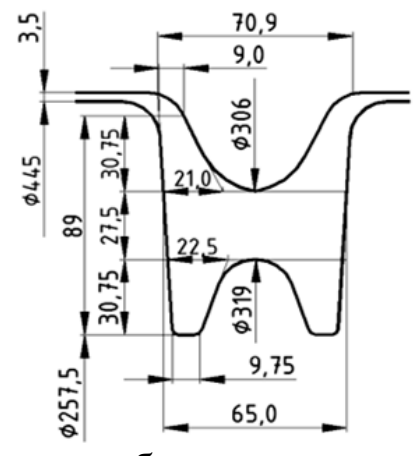

6

Рис. 2. Исходная заготовка (а) и черновой закрытый балочный калибр (б)

Таблица 1

Формоизменение металла при прокатке в черновых закрытых балочных калибрах

\begin{tabular}{|c|c|c|c|c|c|c|c|c|c|c|c|}
\hline $\begin{array}{c}\text { № } \\
\text { п/п }\end{array}$ & $\begin{array}{c}d, \\
\text { мм }\end{array}$ & $\begin{array}{c}B, \\
\text { мм }\end{array}$ & $\begin{array}{c}H, \\
\text { мм }\end{array}$ & $\begin{array}{c}t, \\
\text { мм }\end{array}$ & $\eta_{d}$ & $\eta_{t}$ & $\eta_{H}$ & $\eta_{h o}$ & $\eta_{h з}$ & $B / d$ & $B / H$ \\
\hline 1 & 47,5 & 65,0 & 94,0 & 17,775 & 1,373 & 1,000 & 1,091 & 0,762 & 0,841 & 1,37 & 0,69 \\
\hline 2 & 37,5 & 65,0 & 89,0 & 17,200 & 1,739 & 1,022 & 1,153 & 0,637 & 0,815 & 1,73 & 0,73 \\
\hline 3 & 27,5 & 65,0 & 84,7 & 15,725 & 2,371 & 1,118 & 1,211 & 0,542 & 0,779 & 2,36 & 0,77 \\
\hline 4 & 27,5 & 65,0 & 84,7 & 15,565 & 2,371 & 1,102 & 1,211 & 0,542 & 0,779 & 2,36 & 0,77 \\
\hline 5 & 27,5 & 65,0 & 82,6 & 14,065 & 2,371 & 1,195 & 1,242 & 0,547 & 0,834 & 2,36 & 0,79 \\
\hline 6 & 27,5 & 65,0 & 79,5 & 12,565 & 2,371 & 1,305 & 1,291 & 0,566 & 0,909 & 2,36 & 0,82 \\
\hline 7 & 27,5 & 65,0 & 84,7 & 15,700 & 2,371 & 1,119 & 1,211 & 0,542 & 0,779 & 2,36 & 0,77 \\
\hline 8 & 27,5 & 75,0 & 85,8 & 15,700 & 2,371 & 1,125 & 1,196 & 0,528 & 0,770 & 2,73 & 0,87 \\
\hline 9 & 27,5 & 85,0 & 86,7 & 15,550 & 2,371 & 1,130 & 1,184 & 0,519 & 0,759 & 3,10 & 0,98 \\
\hline 10 & 27,5 & 95,0 & 86,2 & 15,550 & 2,371 & 1,125 & 1,190 & 0,526 & 0,762 & 3,45 & 1,10 \\
\hline 11 & 27,5 & 105,0 & 85,8 & 15,615 & 2,371 & 1,124 & 1,196 & 0,529 & 0,767 & 3,82 & 1,22 \\
\hline 12 & 27,5 & 115,0 & 85,4 & 15,725 & 2,371 & 1,118 & 1,201 & 0,536 & 0,767 & 4,18 & 1,35 \\
\hline 13 & 27,5 & 125,0 & 83,9 & 15,875 & 2,371 & 1,107 & 1,223 & 0,556 & 0,779 & 4,55 & 1,49 \\
\hline 14 & 27,5 & 155,0 & 80,6 & 16,000 & 2,371 & 1,098 & 1,273 & 0,601 & 0,812 & 5,64 & 1,92 \\
\hline 15 & 27,5 & 185,0 & 78,9 & 15,625 & 2,371 & 1,095 & 1,300 & 0,613 & 0,851 & 6,73 & 2,34 \\
\hline
\end{tabular}

В результате моделирования процесса прокатки определены основные параметры формоизменения металла в черновых закрытых калибрах с отношением толщины стенки $d$ к высоте профиля $H$, равным 0,2-0,4. Установлены зависимости высотной утяжки полок, приращения высоты открытых и закрытых фланцев от обжатия стенки, бокового обжатия фланцев и ширины стенки.

На рис. 3-5 приведены графики изменения коэффициентов высотной деформации полок $\eta_{H}$, открытых и закрытых фланцев $\eta_{h o}$ и $\eta_{h s}$ от технологических факторов прокатки обжатия стенки $\eta_{d}$, бокового обжатия фланцев $\eta_{t}$ и ширины стенки (отношения $B / d$ ).

Результаты моделирования обработаны классическими методами регрессионного анализа с использованием программ MathCad14 и SPSS.

В итоге получены следующие регрессионные зависимости интегральных характеристик формоизменения металла в черновых закрытых балочных калибрах, учитывающие влияние бокового обжатия фланцев, обжатия и ширины стенки на изменение высоты фланцев: 


$$
\begin{array}{cl}
\eta_{H}=0,3437+0,2671 \cdot \eta_{d}+0,2117 \cdot \eta_{t}-0,2365 \cdot B / d+0,7231 \cdot B / H & (R=0,99 ; \sigma=0,05), \\
\eta_{h o}=0,7300-0,1151 \cdot \eta_{d}+0,0572 \cdot \eta_{t}-0,1341 \cdot B / d+0,4290 \cdot B / H & (R=0,98 ; \sigma=0,06), \\
\eta_{h 3}=0,1229+0,0403 \cdot \eta_{d}+0,5085 \cdot \eta_{t}-0,2139 \cdot B / d+0,6476 \cdot B / H & (R=0,99 ; \sigma=0,04) .
\end{array}
$$

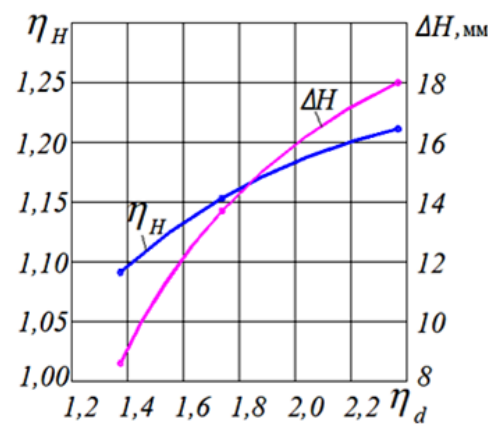

a

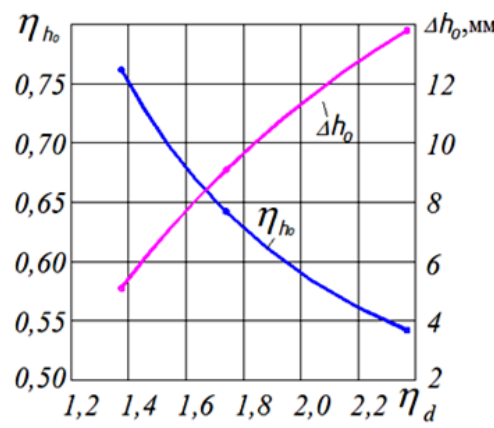

6

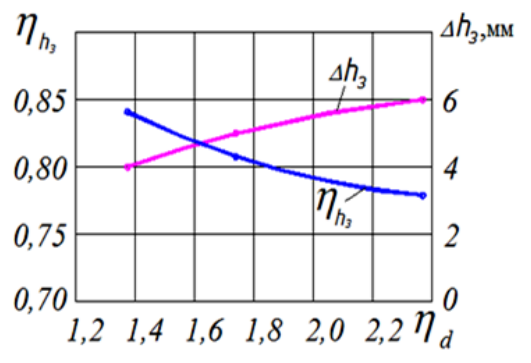

B

Рис. 3. Зависимость высотной деформации полок (а), открытых (б) и закрытых (в) фланцев от обжатия стенки

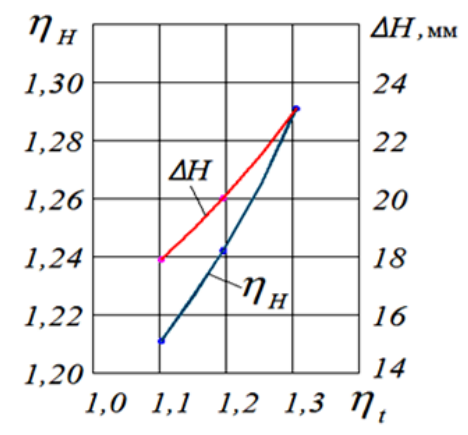

a

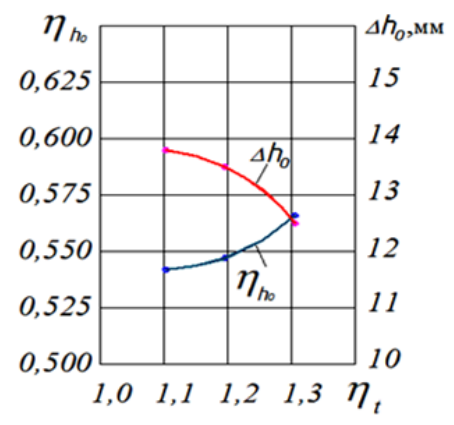

6

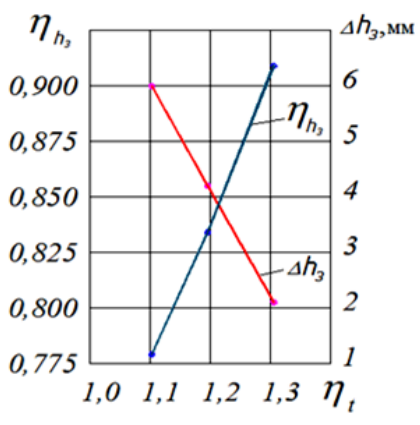

B

Рис. 4. Зависимость высотной деформации полок (а), открытых (б) и закрытых (в) фланцев от бокового обжатия фланцев

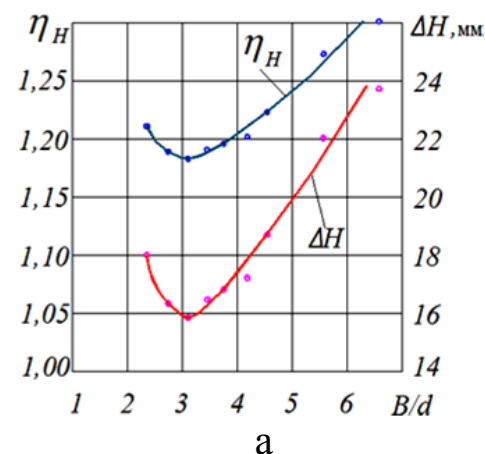

Рис. 5. Зависимость высотной деформаци

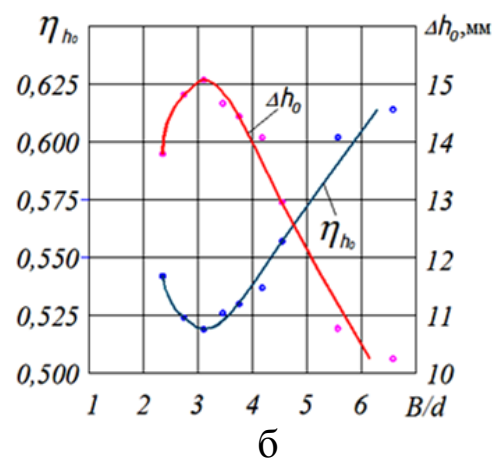

6

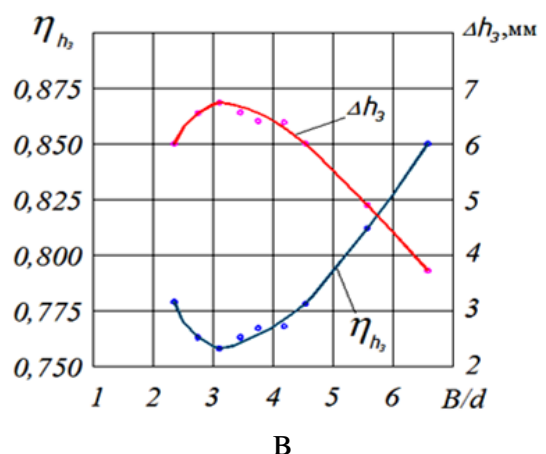

(б) и закрытых (в) фланцев от ширины стенки

Границы варьирования безразмерных параметров прокатки, влияющих на высотную деформацию полок и фланцев, ограничены пределами: $1,373 \leq \eta_{d} \leq 2,371,1,000 \leq \eta_{t} \leq 1,305$, $1,37 \leq B / d \leq 6,73$ и $0,69 \leq B / H \leq 2,34$.

Математическая модель адекватно описывает формоизменение металла в черновых закрытых балочных калибрах и ее рекомендуется использовать на практике при разработке технологии прокатки и рабочих калибровок валков для производства двутавровых профилей повышенной точности. 


\section{ВЫВОДЫ}

Разработана математическая модель расчета интегральных характеристик формоизменения металла (коэффициентов высотной деформации полки, открытого и закрытого фланцев) в зависимости от прямого обжатия стенки, бокового обжатия фланцев и геометрических параметров очага деформации. В основу математической модели положен многофакторный теоретический эксперимент в динамической постановке с варьированием безразмерных технологических параметров прокатки (коэффициента обжатия стенки по толщине, среднего коэффициента бокового обжатия по толщине открытых и закрытых фланцев и отношения ширины стенки к ее толщине) в калибрах с отношением толщины стенки к высоте профиля, равным 0,2-0,4. Полученную математическую модель рекомендуется использовать на практике при разработке рабочих калибровок двутавровых профилей.

\section{СПИСОК ИСПОЛЬЗОВАННОЙ ЛИТЕРАТУРЫ}

1. Теоретическое исследование течения металла в закрытых балочных калибрах методом конечных элементов / В. С. Медведев, П. В. Боровик, В. А. Шиаков, Е. В. Базарова // Обработка материалов давлением : сб. науч. тр. Донбасской государственной машиностроительной академии. - Краматорск : ДГМА, 2014. № 1 (38). - C. 166-172.

2. Медведев В. С. Влияние обжатия стенки на изменение высоты фланцев в черновых закрытых балочных калибрах элементов / В. С. Медведев, Е. В. Базарова, В. А. Шпаков // Вісник Національного технічного університету «ХПI» : зб. наук. пр. Серія: Інформаційні технологї та обладнання обробки матеріалів у машинобудуванні та металургї. - Х. : НТУ «ХПІ», 2014. - № 43 (1086). - С. 81-88.

3. Медведев В. С. Влияние бокового обжатия фланцев на изменение их высоты в черновых закрытых балочных калибрах / В. С. Медведев, Е. В. Базарова // Вестник НТУУ «КПИ» : сб. науч. тр. Серия: Машиностроение. - К. : НТУУ «КПИ», 2016. - № 1 (76). - С. 81-87.

4. Медведев В. С. Влияние ширины стенки на изменение высоты фланцев в черновых закрытых балочных калибрах / В. С. Медведев, Е. В. Базарова, В. А. Шпаков // Обработка материалов давлением : сб. науч. тр. Донбасской государственной машинострочтельной академии. - Краматорск : ДГМА, 2015. - № 1 (40). - С. $175-181$.

5. Медведев В.С. Экспериментальное исследование течения металла в балочных калибрах / В. С. Медведев, В. А. Шпаков, Е. В. Базарова // Ресурсозберігаючі технології виробництва та обробки тиском матеріалів у машинобудуванні : зб. наук. праџь СНУ ім. В. Даля. - Луганськ, 2013. - № 1 (14) .- С. 52-61.

\section{REFERENCES}

1. Teoretycheskoe yssledovanye techenyja metalla $v$ zakrytyh balochnyh kalybrah metodom konechnyh jelementov / V. S. Medvedev, P. V. Borovyk, V. A. Shpakov, E. V. Bazarova // Obrabotka materyalov davlenyem : sb. nauch. tr. Donbasskoj gosudarstvennoj mashynostroytel'noj akademyy. - Kramatorsk : DGMA, 2014. - № 1 (38). - S. $166-172$.

2. Medvedev V. S. Vlyjanye obzhatyja stenky na yzmenenye vysoty flancev v chernovyh zakrytyh balochnyh kalybrah jelementov /V. S. Medvedev, E. V. Bazarova, V. A. Shpakov // Visnyk Nacional'nogo tehnichnogo universytetu «HPI» : zb. nauk. pr. Serija: Informacijni tehnologii' ta obladnannja obrobky materialiv u mashy-nobuduvanni ta metalurgii'. - H. : NTU «HPI», 2014. - № 43 (1086). - S. 81-88.

3. Medvedev V.S. Vlyjanye bokovogo obzhatyja flancev na yzmenenye yh vysoty $v$ chernovyh zakrytyh balochnyh kalybrah / V. S. Medvedev, E. V. Bazarova // Vestnyk NTUU «KPY» : sb. nauch. tr. Seryja : Mashynostroenye. K. : NTUU «KPY», 2016. - № 1 (76). - S. 81-87.

4. Medvedev V.S. Vlyjanye shyryny stenky na yzmenenye vysoty flancev v chernovyh zakrytyh balochnyh kalybrah / V. S. Medvedev, E. V. Bazarova, V. A. Shpakov // Obrabotka materyalov davlenyem : sb. nauch. tr. Donbasskoj gosudarstvennoj mashynostroytel'noj akademyy. - Kramatorsk: DGMA, 2015. - № 1 (40). - S. $175-181$.

5. Medvedev V. S. Jeksperymental'noe yssledovanye techenyja metalla v balochnyh kalybrah / V. S. Medvedev, V. A. Shpakov, E. V. Bazarova // Resursozberigajuchi tehnologii' vyrobnyctva ta obrobky tyskom materialiv u mashynobuduvanni : zb. nauk. prac' SNU im. V. Dalja. - Lugans'k, 2013. - № 1 (14) .- S. 52-61.

Медведев В. С. - д-р техн. наук, гл. науч. сотруд. ГП УкрНТЦ «Энергосталь»; Базарова Е. В. - - ассистент ВНУ им. В. И. Даля.

ГП УкрНТЦ «Энергосталь»- Государственное предприятие «Украинский научнотехнический центр металлургической промышленности «Энергосталь», г. Харьков.

ВНУ им. В. И. Даля - Восточноукраинский национальный университет имени В. И. Даля, г. Северодонецк.

E-mail: mbc1642@ukr.net 